\title{
Genic Microsatellite Markers for Genetic Diversity in Wheat Genotypes
}

\author{
Manisha Kumari, Mukesh Kumar, Vikram Singh, \\ S. Vijay Kumar* and Lakshmi Chaudhary \\ Department of Genetics and Plant Breeding, Chaudhary Charan Singh Haryana Agricultural \\ University, Hisar, 125004, India \\ *Corresponding author
}

\begin{tabular}{|c|}
\hline Keywords \\
\hline $\begin{array}{l}\text { Diversity, } \\
\text { polymorphism, } \\
\text { Simple Sequence } \\
\text { Repeats, Yellow } \\
\text { rust, Wheat }\end{array}$ \\
\hline Article Info \\
\hline $\begin{array}{l}\text { Accepted: } \\
12 \text { August } 2019 \\
\text { Available Online: } \\
\text { 10 September } 2019\end{array}$ \\
\hline
\end{tabular}

\section{Introduction}

Common wheat (Triticum aestivum) $(2 \mathrm{n}=6 \mathrm{x}$ $=42)$ is a versatile cereal crop belongs to family Poaceae, the most diverse and important family of the plant kingdom. It produces large edible grains and provides about one-half of human's food calories and a large part of their nutrient requirements. The substantial increase in world's population demands a consistent increase in the production of wheat. In India, Wheat is the second most important food crop after rice both in terms of area, production and consuming country in the world. Over the last 50 years, Indian agriculture has witnessed spectacular advances in both production and productivity after the introduction of dwarf 
wheat during the mid-sixties. The major states involved in wheat production are Uttar Pradesh, Punjab and Haryana. They account for nearly 70 per cent of the total wheat produced in the country. Punjab and Haryana yield the highest amount of wheat because of the availability of better irrigation facilities and congenial weather condition. Haryana state on the whole has achieved a productivity level of 4.55 tons/ha on 2.5 million hectares (Anonymous, 2018).

Genetic diversity is basis for genetic improvement of crop plant and launching an efficient breeding programme that aimed for the improvement of wheat productivity. Therefore, it is necessary to investigate the genetic diversity in wheat germplasm in order to broaden the genetic variation in future breeding work. The use of molecular marker for evaluation genetic diversity is receiving a much attention (Kumari et al., 2017). Simple sequence repeats (SSRs) (Tautz, 1989) have been widely exploited in wheat due to their high level of polymorphisms, co-dominant inheritance and equal distribution in the wheat genome (Khaled et al., 2015). SSRs are more abundant, ubiquitous in presence, hypervariable in nature and have high polymorphic information content (PIC) (Gupta et al., 2010). SSR have been used to study genetic diversity of wheat cultivars by (Eujay et al., 2001; Grewal et al., 2007; Hai et al., 2007; Ijaz and Khan, 2009; Khaled et al., 2015)

The current research was conducted to estimate the genetic diversity of 49 different wheat genotypes by using 52 microsatellite markers. All the wheat genotypes could be distinguish from each other at molecular level. The phylogenetic relationships, genetic diversity and molecular characteristics concluded in current study will facilitate in breeding programs for the selection of parents and to derive a high yielding yellow rest resistance variety.

\section{Materials and Methods}

\section{Plant materials}

\section{Isolation of genomic DNA}

Genomic DNA was isolated from the young leaves of wheat plants by using CTAB (Cetyl Trimethyl Ammonium Bromide) extraction method given by Murray and Thompson (1980) modified by (Saghai et al., 1984). The concentration and purity of DNA was determined at $260 \mathrm{~nm}$ and $280 \mathrm{~nm}$ by using UV-Vis spectrophotometer. The band quality of genomic DNA was observed with the help of electrophoresis on $0.8 \%$ agarose gel. The DNA samples were diluted to a concentration of $2.0 \mathrm{ng} / \mu \mathrm{l}$ with TE buffer for SSR analysis.

\section{Selection of markers}

A total of 52 molecular markers were used for studying molecular polymorphism in 49 genotypes based on different research paper used in analysis of genetic diversity of wheat. All these primers were custom synthesized from Sigma Chemicals Co. USA. The chromosome locations, base sequences of forward and reverse primers of SSR markers and their annealing temperature are given in (Table 2.)

\section{Microsatellite marker analysis}

PCR amplification reaction was carried out in applied biosystem thermocycler. The optimized PCR reaction contained DNA template $50 \mathrm{ng}, 10 \mathrm{X}$ PCR buffer $2.0 \mu \mathrm{l}, \mathrm{MgCl}_{2}$ $50 \mathrm{mM} 0.6 \mu \mathrm{l}$, dNTPs mix $(10 \mu \mathrm{M}) 0.5 \mu \mathrm{l}$, Forward primer $(10 \mu \mathrm{M}) 0.4 \mu \mathrm{l}$, Reverse primer $\left(\begin{array}{lllll}10 & \mu \mathrm{M}\end{array}\right) \mathrm{m} \quad 0.4 \quad \mu \mathrm{l}, \quad$ Taq DNA Polymerase $(5 \mathrm{U} / \mu \mathrm{l}) 0.3 \mu \mathrm{l}$ in total volume of $20 \mu \mathrm{l}$. The PCR reaction $(20 \mu \mathrm{l})$ was set up in thin walled $0.2 \mathrm{ml} \mathrm{PCR}$ tubes in applied biosystems thermocycler under following reaction conditions: 
$94{ }^{\circ} \mathrm{C}$ for 4 minutes (initial denaturation)

$94{ }^{\circ} \mathrm{C}$ for 1 minute (denaturation)

48.5-73 ${ }^{\circ} \mathrm{C}$ for 1 minute (primer annealing)

$72{ }^{\circ} \mathrm{C}$ for 2 minutes (primer extension)

$72{ }^{\circ} \mathrm{C}$ for 10 minutes (final primer extension)

The amplification reaction was set to repeat the step (ii) to (iv) for 35 times and the amplified products were stored at $-20{ }^{\circ} \mathrm{C}$ till further use. The PCR products were electrophoresed on $2.5 \%$ agarose gels containing at $100 \mathrm{~V}$ for $2 \mathrm{~h}$ and observed under a UV transilluminator.

\section{Allele scoring and data analysis}

The size of amplified band of each microsatellite marker was determined based on electrophoretic mobility relative to molecular weight of ladder (100 bp) used.

Amplified products from microsatellite analysis were scored qualitatively for presence and absence of each marker allele genotype combination. Binary matrix is used for data analysis 1 for present of band and 0 for absence of band.

The binary data was used to calculate similarity genetic distance using JMP 8.0 software, SAS Institute Inc., Carry, NC, 19892007. Dendrogram was constructed by using distance matrix by the unweighted pair group method using arithmetic averages (UPGMA) of JMP 8.0 Software.

Anderson et al., (1993) formula is used for calculating the polymorphic information content (PIC) value of marker which is used in amplification

$$
\mathrm{PIC} i=1-\sum_{j=1}^{k} \mathrm{P}^{2} \mathrm{ij}
$$

Where, Pij is the frequency of the $\mathrm{j}$ th allele for I th marker and summation extends over the alleles.

\section{Results and Discussion}

In the present investigation, a total of 52 SSR primers (including $Y r$ specific primers) were used for amplification in different wheat genotypes as shown in (Table 3). Out of these 52 primers only 49 primers gave amplification and remaining 3 were not amplified. Out of these amplified primers, 22 primers were found to be monomorphic and 27 gave polymorphic bands with a total of 102 alleles amplified with a range of 1-6 per primer. Maximum number of allele was observed in 6 in case of marker Xgwm408 whereas the minimum number of allele is 2 (Barc8, Wmc31, Xgwm341, Gwm11, csLV34, Psp2999, Wmc170, Xgwm95, Xgwm140, Wmc25, Barc76, Xgwm261). PIC values of various SSR loci across all the 49 genotypes ranged from 0.11 (Wmc31) to 0.95 (csLV34).

It is significant to note that 5 out of 27 SSR loci, namely Xpsp 3000, Xwgp249, Wmc 198, csLV34, Xgwm301 revealed PIC values above 0.70 . The detail of PIC values of all 23 markers used in study is presented in (Table 4). Agarose gel displaying allelic polymorphism among wheat genotypes for some of the SSR markers have been shown in (Plates 1.) The size of amplified DNA fragments varied from approx. $100 \mathrm{bp}$ to $500 \mathrm{bp}$. The UPGMA cluster tree analysis led to the grouping of forty nine wheat genotypes in 2 major clusters and 9 sub clusters (Table 5) (Fig 1). Cluster pattern revealed that, subcluster 6 was the largest consisting maximum number of 12 genotypes. This way followed by sub-cluster 4 (8 genotypes), sub-cluster 3 and 8 (6 genotypes), sub-cluster 9 (5), subcluster 1 (4 genotypes), sub-cluster 2 and 7 (3 genotypes) and sub-cluster 5 (2 genotypes).

The development of molecular marker technologies during the last twenty years has revolutionized the genetic analysis of crop plants. 
Today, molecular markers are the best tools used to determine the level of genetic diversity among plants and can provide detailed characterization of genetic resources (Manifesto et al., 2001; Mir et al., 2012). SSR have been used extensively for designing primer sets which are not only highly polymorphic but also species specific (Pestova et al., 2000). Genetic diversity plays an important role in crop improvement and was demonstrated through SSR markers (Gupta et al., 2009; Plaschke et al., 1995) has used wheat microsatellite for the first time for studying the genetic diversity in closely related European bread wheat varieties.

The present study addressed the utility of SSR markers in revealing assessment of genetic variability and diversity at the molecular level among 49 wheat genotypes wherein 52 SSR primers were used, which were earlier identified in the genomic regions of $\mathrm{A}, \mathrm{B}$, and D genomes of wheat. The SSR marker loci generated by the 49 primer pairs were used to assess the genetic diversity among 49 wheat genotypes. The microsatellite or SSR primers generated 102 alleles with the number of alleles per locus varying from 0 to 6 . Maximum number of allele was observed in 6 in case of marker Xgwm408 whereas the minimum number of allele is 2 (Barc8, Wmc31, Xgwm341, Gwm11, csLV34, Psp2999, Wmc170, Xgwm95, Xgwm140, Wmc25, Barc76, Xgwm261). A similar pattern of allelic variation was also observed earlier (Schuster et al., 2009; Emon et al., 2010; Zhang et al., 2011). Contrarily the number of alleles detected in the present study was significantly higher than the average number of alleles in previous reports (Schuster et al., 2009) which has reported 3.2. The presence of unique alleles in the set of cultivars may indicate that these materials are useful for plant breeders and geneticists as a rich source of genetic diversity for wheat.
The PIC value is a reflection of allele diversity and frequency among the wheat cultivars and also varied from one locus to another locus.

The level of polymorphism determined by PIC values was quite high and varied range 0.11 (Wmc31) to 0.95 (csLV34).

It is note that 5 out of 27 SSR loci, namely Xpsp 3000, Xwgp249, Wmc 198, csLV34, Xgwm301 revealed PIC values above 0.70, can be considered highly useful for differentiation of wheat genotypes. Similarly, (Ijaz and Khan 2009) reported high level of polymorphism ranging from $10.52 \%$ to 98.42\%. (Manifesto et al., 2001) reported PIC values ranged from 0.40 to 0.84 with an average value of 0.72 .

The DNA fragments varied from approx. 100 bp to 500bp. Similarly, (Abbas et al., 2008) obtained amplified DNA fragments that varied in size ranging from $250 \mathrm{bp}$ to $1000 \mathrm{bp}$ and (Manifesto et al., 2001) obtained amplified DNA fragments that varied in size from $115 \mathrm{bp}$ to $285 \mathrm{bp}$.

Cluster analysis using UPGMA method delineated the 49cultivars into 2 main clusters and 9 sub clusters. Cluster pattern revealed that, sub-cluster 6 was the largest consisting maximum number of 12 genotypes. 9 subclusters showing the effectiveness of microsatellite markers in genetic diversity assays.

Several studies using SSR have resulted in successful clustering of wheat cultivars (Amer et al., 2001; Zhang et al., 2005; Hao et al., 2008; Ijaz and Khan et al., 2009; Schuster et al., 2009). This type of markers is very effective in delineating diversity based on parental source by grouping cultivars with similar pedigree information as well as grouping based on agronomic characteristics and geographical origin. 
Fig.1 Dendrogram showing the clustering pattern of forty nine genotypes of wheat on the basis of SSR marker

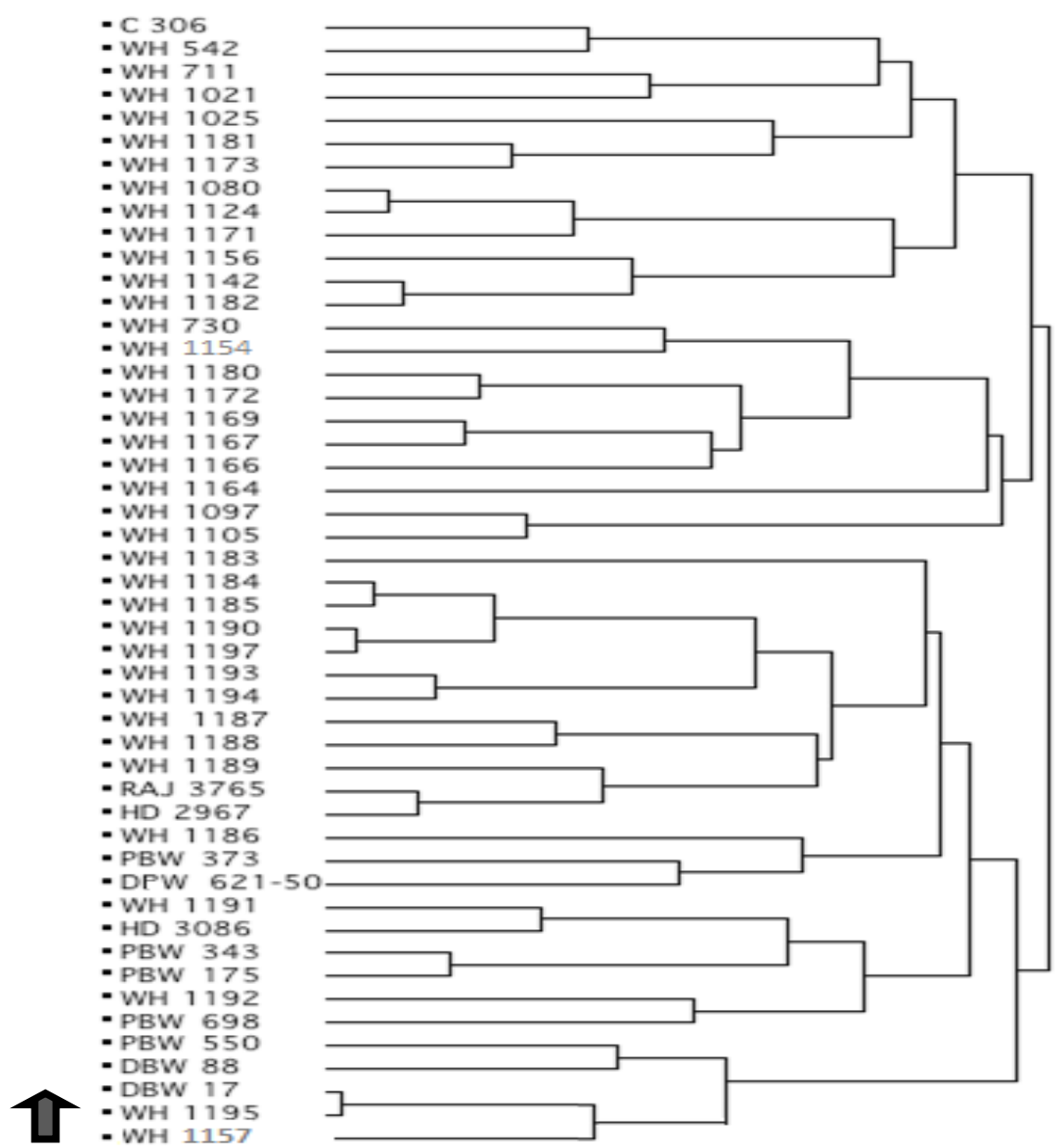

Plate.1 Polymorphism in different forty nine genotypes of wheat by using primer Xgwm349

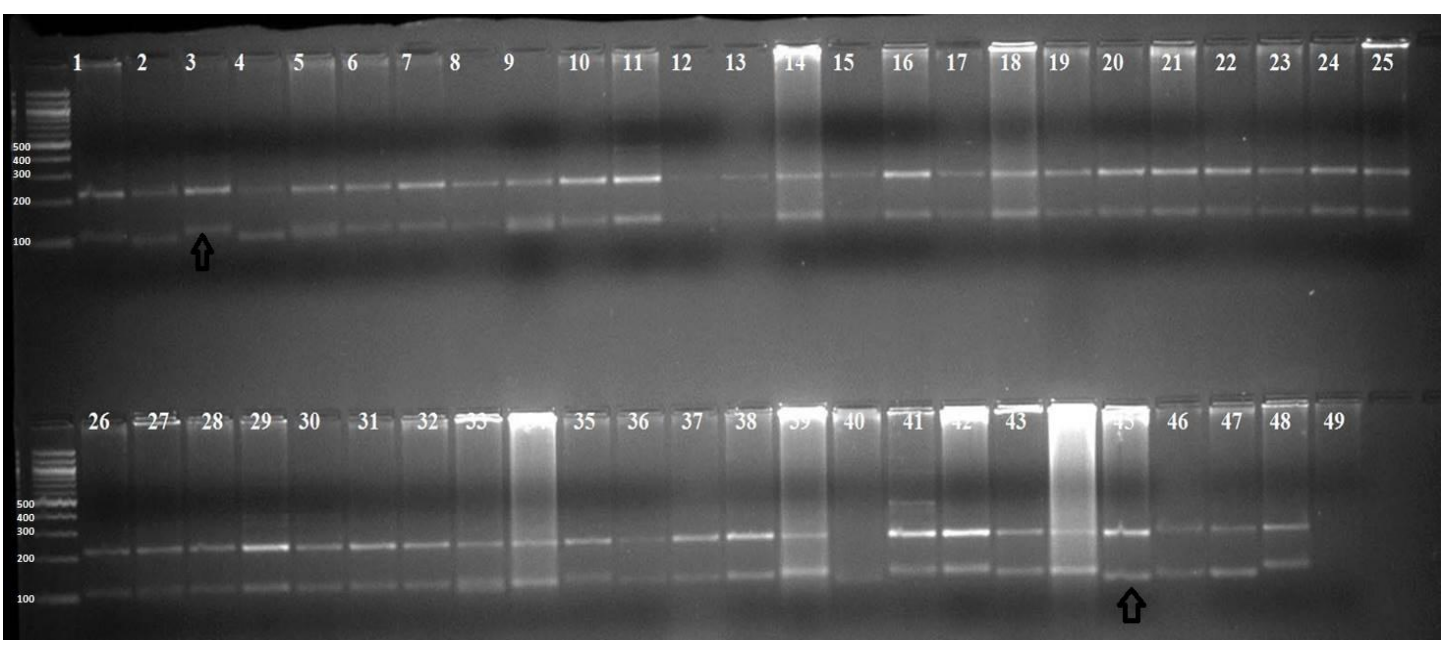


Plate.2 Polymorphism in different forty nine genotypes of wheat by using primer csLV34

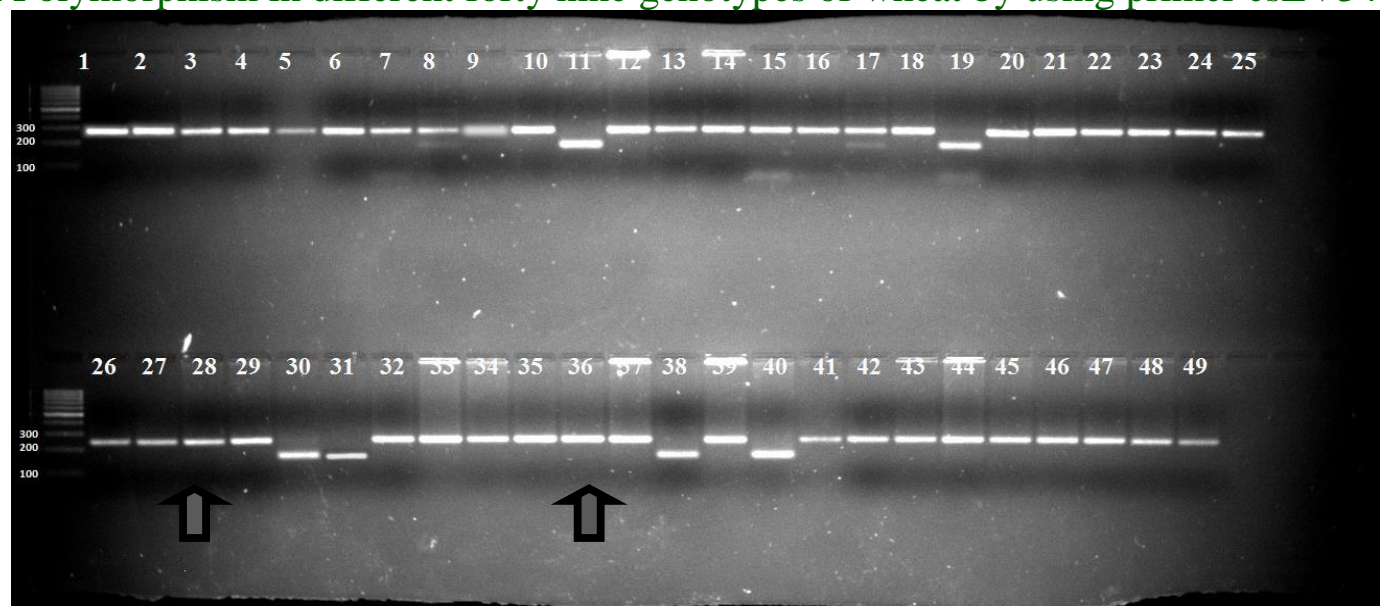

Plate.3 Polymorphism in different forty nine genotypes of wheat by using primer GWM11

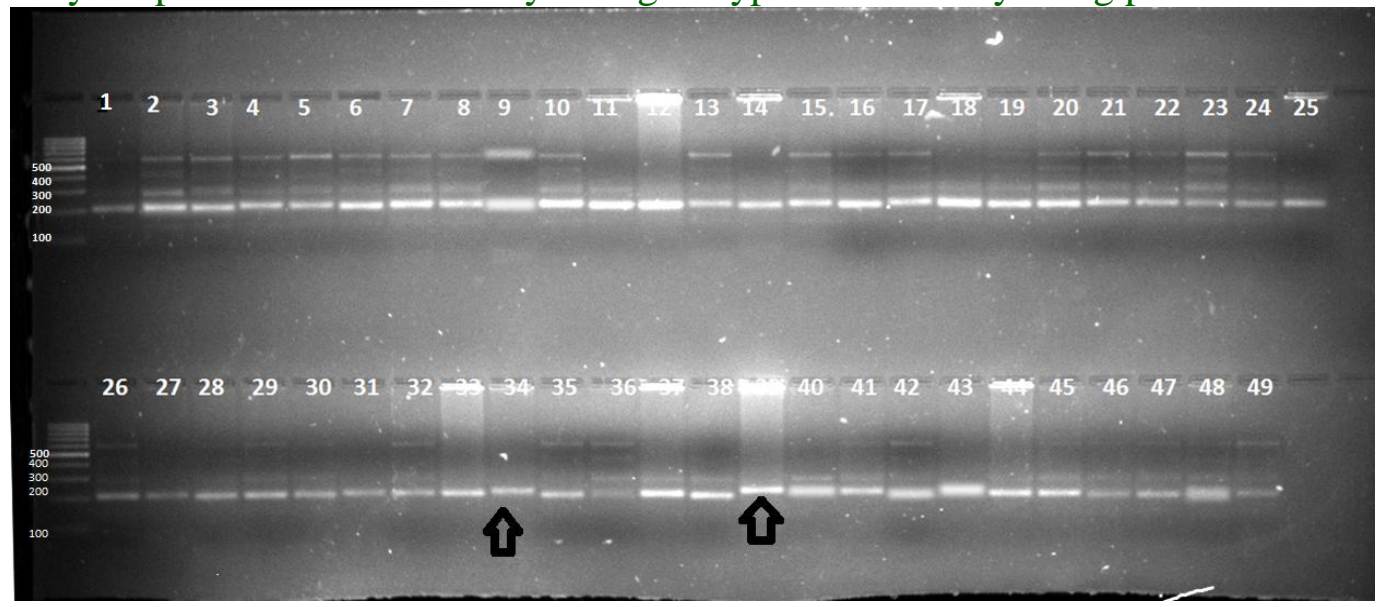

Table.1 List of all the 49 wheat genotypes under experiment

\begin{tabular}{|c|c|c|c|c|c|}
\hline SR.NO. & GENOTYPE & SR.NO. & GENOTYPE & SR.NO. & GENOTYPE \\
\hline $\mathbf{1}$ & C -306 & 18 & WH 1166 & 35 & WH 1193 \\
\hline $\mathbf{2}$ & WH-542 & 19 & WH 1164 & 36 & WH 1194 \\
\hline $\mathbf{3}$ & WH 711 & 20 & WH 1157 & 37 & WH 1197 \\
\hline $\mathbf{4}$ & WH 730 & 21 & WH 1156 & 38 & RAJ 3765 \\
\hline $\mathbf{5}$ & WH 1021 & 22 & WH 1154 & 39 & PBW 698 \\
\hline $\mathbf{6}$ & WH 1025 & 23 & WH 1142 & 40 & PBW 550 \\
\hline $\mathbf{7}$ & WH 1080 & 24 & WH 1182 & 41 & PBW 373 \\
\hline $\mathbf{8}$ & WH 1097 & 25 & WH 1183 & 42 & PBW 343 \\
\hline $\mathbf{9}$ & WH 1105 & 26 & WH 1184 & 43 & PBW 175 \\
\hline $\mathbf{1 0}$ & WH 1124 & 27 & WH 1185 & 44 & HD 3086 \\
\hline $\mathbf{1 1}$ & WH 1181 & 28 & WH 1186 & 45 & HD 2967 \\
\hline $\mathbf{1 2}$ & WH 1180 & 29 & WH 1187 & 46 & DPW 621-50 \\
\hline $\mathbf{1 3}$ & WH 1173 & 30 & WH 1188 & 47 & DBW 88 \\
\hline $\mathbf{1 4}$ & WH 1172 & 31 & WH 1189 & 48 & DBW 17 \\
\hline $\mathbf{1 5}$ & WH 1171 & 32 & WH 1190 & 49 & WH 1195 \\
\hline $\mathbf{1 6}$ & WH 1169 & 33 & WH 1191 & & \\
\hline $\mathbf{1 7}$ & WH 1167 & 34 & WH 1192 & & \\
\hline
\end{tabular}


Table .2 List of 52 SSR markers (including Yr specific markers) used for studying polymorphism in 49 genotypes

\begin{tabular}{|c|c|c|c|c|c|}
\hline $\begin{array}{l}\text { S. } \\
\text { No }\end{array}$ & SSR Marker & Linkage group & Forward Primer sequence & Reverse Primer sequence & $\begin{array}{c}\text { Ta } \\
\left({ }^{\circ} \mathbf{C}\right)\end{array}$ \\
\hline 1 & Xbarc7-2B & $2 \mathrm{~B}$ & GCGAAGTACCACAAATTTGAAGGA & CGCCATCTTACCCTATTTGATAACTA & 51.5 \\
\hline 2 & Xbarc8 & 1B (Yr15) & GCGGGAATCATGCATAGGAAAACAGAA & GCGGGGGCGAAACATACACATAAAAAA & 58 \\
\hline 4 & Xbarc101 & 3B (Yr36) & GCTCCTCTCACGATCACGCAAAG & GCGAGTCGATCACACTATGAGCCAATG & 54 \\
\hline 5 & Xbarc181 & 1B (Yr26) & CGCTGGAGGGGGTAAGTCATCAC & CGCAAATCAAGAACACGGGAGAAAGAA & 60 \\
\hline 6 & Xbarc167 & & AAAGGCCCATCAACATGCAAGTACC & CGCAGTATTCTTAGTCCCTCAT & 65.2 \\
\hline 7 & Xbarc187 & 1BYr24 & GTGGTATTTCAGGTGGAGTTGTTTTA & CGGAGGAGCAGTAAGGAAGG & 62 \\
\hline 8 & IAG95-STS & Yr9/Lr26/Sr34 & CGAATAGCCGCTGCACAAG & TATGCATGCCTTTCTTTACAAT & 51 \\
\hline 9 & Xbarc59 & & GCGTTGGCTAATCATCGTTCCTTC & AGCACCCTACCCAGCGTCAGTCAAT & 69 \\
\hline 10 & Xbarc76 & & ATTCGTTGCTGCCACTTGCTG & GCGCGACACGGAGTAAGGACACC & 69.5 \\
\hline 11 & Xbarc137 & 1B & GGCCCATTTCCCACTTTCCA & CCAGCCCCTCTACACATTTT & 61 \\
\hline 12 & Xbarc352 & & CCCTTTCTCGCTCGCCTATCCC & CTGTTTCGCCCAATCTCGGTGTG & 64 \\
\hline 13 & Xgwm261 & $2 \mathrm{D}$ & CTCCCTGTACGCCTAAGGC & CTCGCGCTACTAGCCATTG & 62 \\
\hline 14 & Xgwm273 & 1B(YrH52) & ATTGGACGGACAGATGCTTT & AGCAGTGAGGAAGGGGATC & 52.5 \\
\hline 15 & Xgwm297 & $2 \mathrm{D}$ & GCGTAGGAGAGATGCCCCAAAGGTT & GCGTGCGGACTCGTGAATCATTAC & 54.5 \\
\hline 16 & Xgwm408 & $5 B$ & TCGATTTATTTGGGCCACTG & GTATAATTCGTTCACAGCACGC & 63.9 \\
\hline 17 & Xgwm437 & 7D & GATCAAGACTTTTGTATCTCTC & GATGTCCAACAGTTAGCTTA & 54.2 \\
\hline 18 & Xgwm186 & $5 \mathrm{~A}$ & GCAGAGCCTGGTTCAAAAAG & CGCCTCTAGCGAGAGCTATG & 58.5 \\
\hline 19 & Xgwm413 & 1B (Yr15) & TGCTTGTCTAGATTGCTTGGG & GATCGTCTCGTCCTTGGCA & 52.5 \\
\hline 20 & Xgwm18 & 1B (Yr26) & TGGCGCCATGATTGCATTATCTTC & GGTTGCTGAAGAACCTTATTTAGG & 50 \\
\hline 21 & Xgwm359 & $2 \mathrm{~A}$ & CTAATTGCAACAGGTCATGGG & TACTTGTGTTCTGGGACAATGG & 58 \\
\hline 22 & Barc72 & & CGTCCTCССССТCTCAATCTACTCTC & CGTCCCTCCATCGTCTCATCA & 68 \\
\hline 23 & Barc353 & & GAAGTTCCCAAAATGCCTCTGTC & GCGGATCGAAGACCTAAGAAAAG & 71 \\
\hline 24 & Xwmc120 & & GGAGATGAGAAGGGGGTCAGGA & CCAGGAGACCAGGTTGCAGAAG & 67.5 \\
\hline 25 & wmc364 & Yr2 & ATCACAATGCTGGCCCTAAAAC & CAGTGCCAAAATGTCGAAAGTC & 52 \\
\hline 26 & Xwmc44 & Yr29 & GGTCTTCTGGGCTTTGATCCTG & TGTTGCTAGGGACCCGTAGTGG & 60 \\
\hline 27 & Xwgp8 & 1B (Yr9) & CTCTGTATACGAGTTGTC & GAGGAAGCACAGGTTGCC & 62 \\
\hline 28 & Xgwm16 & $2 \mathrm{~B} / 5 \mathrm{D} / 7 \mathrm{~B}$ & GCTTGGACTAGCTAGAGTATCATAC & CAATCTTCAATTCTGTCGCACGG & 62 \\
\hline 29 & Xgwm249 & 2A (Yr16) & CAAATGGATCGAGAAAGGGA & CTGCCATTTTTCTGGATCTACC & 48 \\
\hline 30 & csLV34 & Yr18/Lr26/Sr39 & CTTGGTTAAGACTGGTGATGG3 & TGCTTGCTATTGCTGAATAGT3 & 62 \\
\hline
\end{tabular}




\begin{tabular}{|l|l|c|l|l|c|}
\hline 31 & GWM11 & Yr15/Yr24 & GGATAGTCAGACAATTCTTGT & GTGAATTGTGTCTTGTATGCTTCC \\
\hline 32 & Xgwm 6 & 4B & CGTATCACCTCCTAGCTAAACTAG & AGCCTTATCATGACCCTACCTT \\
\hline 33 & Xgwm 37 & 7D & ACTTCATTGTTGATCTTGCATG & CGACGAATTCCCAGCTAAAC \\
\hline 34 & Xgwm 120 & Yr5 & GATCCACCTTCCTCTCTCTC & GATTATACTGGTGCCGAAAC \\
\hline 35 & Xgwm 140 & Yr29 & ATGGAGATATTTGGCCTACAAC & CTTGACTTCAAGGCGTGACA \\
\hline 36 & Xgwm 192 & 5D & GGTTTTCTTCAGATTGCGC & CGTTGTCTAATCTTGCCTTGC \\
\hline 37 & Xgwm 210 & 2B/5D/7B & TGCATCAAGAATAGTGTGGAAG & TGAGAGGAAGGCTCACACCT \\
\hline 38 & Xgwm 301 & 2D & GAGGAGTAAGACACATGCCC & GTGGCTGGAGATTCAGGTTC \\
\hline 39 & Xgwm 319 & 2B & GGTTGCTGTACAAGTGTTCACG & CGGGTGCTGTGTGTAATGAC \\
\hline 40 & Xgwm 349 & 2D & GGCTTCCAGAAAACAACAGG & ATCGGTGCGTACCATCCTAC \\
\hline 41 & Xgwm146 & 7B & CCAAAAAAACTGCCTGCATG & CTCTGGCATTGCTCCTTGG \\
\hline 42 & Xgwm268 & 1B & AGGGGATATGTTGTCACTCCA & TTATGTGATTGCGTACGTACCC \\
\hline 43 & Xgwm537 & 7B & ACATAATGCTTCCTGTGCACC & GCCACTTTTGTGTCGTTCCT \\
\hline 44 & Xgwm569 & 7B & GGAAACTTATTGATTGAAAT & TCAATTTTGACAGAAGAATT \\
\hline 45 & Xgwm577 & 7B & ATGGCATAATTTGGTGAAATTG & TGTTTCAAGCCCAACTTCTATT \\
\hline 46 & Xgwm247 & 2B & GCAATCTTTTTCTGACCACG & ATGTGCATGTCGGACGC \\
\hline 47 & Xgwm341 & 3D & TTCAGTGGTAGCGGTCGAG & CCGACATCTCATGGATCCAC \\
\hline 48 & Xwmc25 & 2D & TCTGGCCAGGATCAATATTACT & TAAGATACATAGATCCAACACC \\
\hline 49 & Xwmc31 & & CTGTTGCTTGCTCTGCACCCTT & GTTCAAGTGGTCATTGTTGCT \\
\hline 50 & Xwmc170 & 2A & ACATCCACGTTTATGTTGTTGC & TTGGTTGCTCAACGTTTACTTC \\
\hline 51 & Xwmc89 & 6A & ATGTCCACGTGCTAGGGAGGTA & TTGCCTCCCAAGACGAAATAAC \\
\hline 52 & Xwmc198 & Yr32 & CACGCTGCCATCACTTTTAC & TTGAAGTGGTCATTGTTGCT \\
\hline
\end{tabular}

Ta $\left({ }^{0} \mathrm{c}\right)$ - annealing temperature 
Table.3 List of SSR marker primers showing amplification in different wheat genotypes

\begin{tabular}{|c|c|c|c|c|c|}
\hline S.No. & SSR Marker & Amplification Result & S.No. & SSR Marker & Amplification Result \\
\hline 1 & $X b \operatorname{arc} 7-2 B$ & M & 27 & Xwgp8 & M \\
\hline 2 & Xbarc8 & $\mathrm{P}$ & 28 & Xgwm16 & M \\
\hline 3. & Xbarc101 & M & 29 & Xgwm249 & $\mathrm{P}$ \\
\hline 4. & Xbarc181 & M & 30 & $\operatorname{csLV} 34$ & $\mathrm{P}$ \\
\hline 5. & Xbarc 167 & M & 31 & GWM11 & $\mathrm{P}$ \\
\hline 6. & Xbarc 187 & M & 32 & Xgwm 6 & M \\
\hline 7. & IAG95-STS & $\mathrm{P}$ & 33 & Xbarc137 & $\mathrm{P}$ \\
\hline 8. & Xbarc59 & NA & 34 & Xgwm 120 & M \\
\hline 9. & Xbarc76 & $\mathrm{P}$ & 35 & Xgwm 140 & $\mathrm{P}$ \\
\hline 10. & Xbarc137 & $\mathrm{P}$ & 36 & Xgwm 192 & M \\
\hline 11. & Xbarc 352 & M & 37 & Xpsp3000 & $\mathrm{P}$ \\
\hline 12 & Xgwm261 & M & 38 & Xgwm 301 & $\mathrm{P}$ \\
\hline 13 & Xgwm273 & $\mathrm{P}$ & 39 & Xgwm 319 & $\mathrm{P}$ \\
\hline 14 & Xgwm297 & M & 40 & Xgwm 349 & $\mathrm{P}$ \\
\hline 15 & Xgwm408 & $\mathrm{P}$ & 41 & Xgwm146 & $\mathrm{P}$ \\
\hline 16 & Xgwm437 & M & 42 & Xgwm268 & $\mathrm{P}$ \\
\hline 17 & Xgwm186 & M & 43 & Xgwm537 & M \\
\hline 18 & Xgwm413 & M & 44 & Xgwm569 & NA \\
\hline 19 & Xgwm 18 & M & 45 & Xgwm577 & $\mathrm{P}$ \\
\hline 20 & Xgwm 210 & M & 46 & Xgwm247 & M \\
\hline 21 & Barc72 & M & 47 & Xgwm341 & $\mathrm{P}$ \\
\hline 22 & Barc353 & M & 48 & $X w m c 25$ & $\mathrm{P}$ \\
\hline 23 & Xwmc120 & M & 49 & Xwmc 31 & $\mathrm{P}$ \\
\hline 24 & wmc 364 & M & 50 & Xwmc170 & $\mathrm{P}$ \\
\hline 25 & $X w m c 44$ & $\mathrm{P}$ & 51 & Psp2999 & $\mathrm{P}$ \\
\hline 26 & Xgwm95 & $\mathrm{P}$ & 52 & Xwmc198 & $\mathrm{P}$ \\
\hline
\end{tabular}


Table.4 Range and PIC value of polymorphic SSR primers

\begin{tabular}{|c|c|c|c|c|}
\hline & Primer name & No. Of Alleles & Range (bp) & PIC values \\
\hline 1 & Xpsp 3000 & 5 & $180-300$ & 0.75 \\
\hline 2 & Barc8 & 2 & $280-500$ & 0.49 \\
\hline 3 & Xwgp249 & 4 & $100-500$ & 0.75 \\
\hline 4 & Xgwm273 & 3 & $200-400$ & 0.66 \\
\hline 5 & Wmc31 & 2 & $100-170$ & 0.11 \\
\hline 6 & Wmc 198 & 4 & $160-500$ & 0.72 \\
\hline 7 & IAG95-STS & 3 & $100-210$ & 0.58 \\
\hline 8 & Xgwm341 & 2 & $140-180$ & 0.50 \\
\hline 9 & Gwm11 & 2 & $200-210$ & 0.19 \\
\hline 10 & csLV34 & 2 & $180-280$ & 0.95 \\
\hline 11 & Xgwm349 & 3 & $100-210$ & 0.53 \\
\hline 12 & Psp2999 & 2 & $180-190$ & 0.23 \\
\hline 13 & Wmc170 & 2 & $220-230$ & 0.21 \\
\hline 14 & Xgwm95 & 2 & $110-120$ & 0.48 \\
\hline 15 & Xgwm140 & 2 & $210-210$ & 0.30 \\
\hline 16 & Xgwm268 & 3 & $200-300$ & 0.29 \\
\hline 17 & Wmc25 & 2 & $180-210$ & 0.36 \\
\hline 18 & Xgwm577 & 4 & $100-200$ & 0.53 \\
\hline 19 & Xgwm319 & 3 & $120-210$ & 0.66 \\
\hline 20 & Barc76 & 2 & $210-220$ & 0.40 \\
\hline 21 & Barc137 & 3 & $200-500$ & 0.61 \\
\hline 22 & Xgwm44 & 3 & $200-500$ & 0.40 \\
\hline 23 & Xgwm146 & 3 & $160-400$ & 0.47 \\
\hline 24 & Xgwm674 & 5 & $150-500$ & 0.60 \\
\hline 25 & Xgwm261 & 2 & $180-200$ & 0.50 \\
\hline 26 & Xgwm301 & 6 & $160-160$ & 0.77 \\
\hline 27 & Xgwm408 & 3 & $180-200$ & 0.32 \\
\hline
\end{tabular}


Table.5 Distribution of forty nine wheat genotypes in different clusters based on SSR markers

\begin{tabular}{|c|c|c|c|}
\hline Major cluster & Sub- clusters & Genotypes & $\begin{array}{c}\text { No of } \\
\text { genotypes }\end{array}$ \\
\hline \multirow[t]{5}{*}{ Cluster A } & Cluster1 & C306, WH542,WH711,WH1021 & 4 \\
\hline & Cluster2 & WH1025,WH1181,WH1173 & 3 \\
\hline & Cluster3 & WH1080,WH1124,WH1171,WH1156,WH1142,WH1182, & 6 \\
\hline & Cluster4 & $\begin{array}{l}\text { WH730, WH1154, WH1180, WH1172, WH1169, WH1167, } \\
\text { WH1166, WH1164 }\end{array}$ & 8 \\
\hline & Cluster5 & WH1097,WH1105 & 2 \\
\hline \multirow[t]{4}{*}{ Cluster B } & Cluster6 & $\begin{array}{l}\text { WH1183,WH1184,WH1 185,WH1190,WH1 197,WH1193, } \\
\text { WH1194,WH1187,WH1188,WH1 189,RAJ3765,HD2967 }\end{array}$ & 12 \\
\hline & Cluster7 & WH1186, DBW621-50, PBW373 & 3 \\
\hline & Cluster8 & WH1191, PBW698, HD3086, PBW343, PBW175, WH1192 & 6 \\
\hline & Cluster9 & PBW550, WH1195, DBW88, DBW17, WH1157 & 5 \\
\hline
\end{tabular}

Genetic diversity evaluation serves as a crucial platform in plant improvement. In the present study 52 Simple Sequence Repeat (SSR) primer sets were used to characterize 49 wheat varieties to know about the diverse varieties for future breeding programs to enhance wheat production. Microsatellites displayed a high level of polymorphism in the present study. The information about the genetic diversity of these wheat cultivars will be much useful for proper identification and selection of appropriate parents for use in the breeding programs, including gene mapping for wheat improvement, enhance the breeding efficiency and will add the strength of marker assisted selection (MAS).

\section{References}

Abbas, S.J., Rehmat, S., Shah, U., Rasool, G. and A. Iqbal: Analysis of genetic diversity in Pakistani wheat varieties by using Simple Sequence Repeat (SSR) primer sets. J. Sust. Agri., 2 (1), 34-37 (2008).

Amer, I.M.B., Borner, A. and M.S. Roder: Detection of genetic diversity in Labyan wheat genotypes using wheat microsatellite marker. Genet. Res. Crop Evol., 48, 179-585 (2001).

Anonymous: Progress report of all India coordinated wheat and barley improvement project 2014-15. Crop improvement, Directorate of Wheat Research, Karnal, India (2015).

Emonn, R., Gustafson, J., Nguyen, H., Musket, T., Jahiruddin, M., Islam, M., Haque, M. S., Islam, M. M., Begum, S. N. and M. M. Hassan: Molecular markerbased characterization and genetic diversity of wheat genotypes in relation to Boron use efficiency. Ind. J. Genet., 70(4), 339-348 (2010).

Eujay, I., Sorrells, M., Baum, M., Woltersand, P. and W. Powell: Assessment of genotypic variation among cultivated durum wheat based on EST-SSRs and genomic SSRs. Euphytica, 119, 39-43 (2001).

Grewal, S., Kharb, P., Malik, R., Jain, S and R. Jain: Assessment of genetic diversity among some Indian wheat cultivars using random amplified polymorphic DNA (RAPD) markers. Ind. J. Biotech., 6, 1823 (2007). 
Gupta, P., Langridge, P. and R. Mir: Markerassisted wheat breeding: present status and future possibilities. Mole. Breed., 26 (10), 145-161 (2010).

Gupta, S.K., Cherpe, A., Prabhu, K. V. and Q.M.R. Haque: Identification and validation of molecular marker linked to leaf rust resistance gene Lrl9 in wheat. Theor. Appl. Genet., 13, 1027-1036 (2006).

Hai, L., Wagner, C. and W. Friedt: Quantitative structure analysis of genetic diversity among spring bread wheats (Triticum aestivum L.) from different geographical regions. Genetica, 130, 213225 (2007).

Hao, Y.F., Liu, A.F., Wang, Y.H., Feng, D.S., Gao, J.R., Li, X.F., Liu, S.B. and H.G. Wang: Pm23: a new allele of Pm4 located on chromosome 2AL in wheat. Theor. Appl. Genet., 117, 1205-1212 (2008).

Ijaz, S. and I.A. Khan: Molecular characterization of wheat germplasm using microsatellite markers. Genet. Mole. Res., 8 (3), 809-815 (2009).

Khaled, F., Salem, M., Röder, M. S. and A. Börner: Assessing genetic diversity of Egyptian hexaploid wheat (Triticum aestivum L.) using microsatellite markers. Genet. Res. Crop Evol., 62(3), 377-385 (2015).

Kumari, M., Kumar, M., Singh, V., Kumar S, V. and M. Rathi: Trait association and morphological diversity in wheat (Triticum aestivum L.) genotypes. Elect. J. Pl. Breed., 8(2), 534-540 (2017).

Manifesto, M.M., Schlatter, A.R., Hopp, H.E., Suarez, E.Y. and J. Dubcovsky:
Quantitative evaluation of genetic diversity in wheat germplasm using molecular markers. Crop Sci., 41, 682690 (2011).

Mir, R.R., Kumar, J., Balyan. H.S. and P. K. Gupta: A study of genetic diversity among Indian bread wheat (Triticum aestivum L.) cultivars released during last 100 years. Genet. Res. Crop Evol., 59 (5), 717-726 (2012).

Murphy, L. R., Santra, D., Kidwell, K., Yan, G., Chen, X. and K. G. Campbell: Linkage maps of wheat stripe rust resistance genes $\operatorname{Yr} 5$ and $\operatorname{Yr} 15$ for use in marker-assisted selection. Crop Sci., 49, 1786-1790 (2009).

Saghai-Maroof, M.A., Soliman, K. M., Jorgensen, R.A. and R.W. Allard: Ribosomal DNA spacer-length polymorphism in Barley: Mendelian inheritance, Chromosomal-location and population dynamics. Proc. Nat. Acad. Sci., 81, 8014-8019 (1984).

Schuster, I., Vieira, E.S.N., Silva G.J., Franco, F.A. and V.S. Marchioro: Genetic variability in Brazilian wheat cultivars assessed by microsatellite markers. Genet. Mol. Biol., 32 (3), 557-563 (2009).

Tautz, D.: Hypervariability of simple sequences as a general source of polymorphic DNA markers. Nucl. Acids Res., 17, 6463-6471 (1989).

Zhang, P., Li, J., Li, X., Liu, X., Zhao, X. and Y. Lu: Population structure and genetic diversity in a rice core collection (Oryza sativa) investigated with SSR markers. Plos One. 6(12), e27565 (2011)

\section{How to cite this article:}

Manisha Kumari, Mukesh Kumar, Vikram Singh, Vijay Kumar S and Lakshmi Chaudhary 2019. Genic Microsatellite Markers for Genetic Diversity in Wheat Genotypes. Int.J.Curr.Microbiol.App.Sci. 8(09): 1220-1231. doi: https://doi.org/10.20546/ijcmas.2019.809.140 